\title{
DELIBERAÇÃO PÚBLICA E A REDUÇÃO DO DÉFICIT DEMOCRÁTICO DO SISTEMA REPRESENTATIVO
}

Tiago Cordeiro Nogueira*

\section{RESUMO}

O presente artigo tem por objetivo geral identificar as deficiências do sistema representativo e apresentar a deliberação pública como instrumento indispensável à mitigação do déficit democrático. Os objetivos específicos são divididos em tópicos. No primeiro, demonstra-se a origem da democracia moderna. No segundo, analisa-se a expansão do poder democrático e a influência dos poderes ocultos. Em seguida, apresenta-se falhas do sistema representativo e identificada a existência de filtros à vontade popular. E, por fim, investiga-se o potencial da democracia deliberativa para a redução do déficit democrático. Utilizou-se o método indutivo e as técnicas do fichamento e da pesquisa bibliográfica.

Palavras-chave: Déficit democrático; Deliberação pública; Democracia moderna; Sistema representativo; Sociedade contemporânea.

\section{PUBLIC DELIBERATION AND THE REDUCTION OF THE DEMOCRATIC DEFICIT OF THE REPRESENTATIVE SYSTEM}

\begin{abstract}
The general purpose of this article is to identify the deficiencies of the representative system and present public deliberation as an indispensable instrument for mitigating the democratic deficit. Specific objectives are divided into topics. First, the origin of modern democracy is demonstrated. Secondly, the expansion of democratic power and the influence of occult powers are analyzed. Then, failures of the representative system are presented and the existence of filters to popular will is identified. Finally, the potential of deliberative democracy to reduce the democratic deficit is investigated. The inductive method and the techniques of file and bibliographic research were used.
\end{abstract}

Keywords: Democratic deficit; Public deliberation; Modern democracy; Representative system; Contemporary society.

\section{INTRODUÇÃO}

Neste século de expansão das tecnologias de informação nos meios de comunicação de massa, cuja consequência observada é a transcendência das fronteiras territoriais e eliminação das distâncias, afigura-se necessário discutir a importância da deliberação pública para o aperfeiçoamento da democracia moderna, sobretudo por propiciar o exercício de uma

\footnotetext{
*Mestrando em Ciência Jurídica pela Universidade do Vale do Itajaí - UNIVALI. Procurador do Estado de Rondônia. Porto Velho/RO, Brasil. E-mail: tiagocno@hotmail.com.
} 
cidadania mais participativa e diretamente influente no processo de formação das decisões coletivas.

Tal questão tornou-se sobremodo imperativa diante da complexa sociedade contemporânea que se apresenta aos dirigentes políticos e porque, somado a essa circunstância, a tradicional dimensão representativa da democracia moderna apresenta algumas insuficiências que lhe são inerentes, como a ficção da soberania popular e do autogoverno, e promessas não cumpridas, como a eliminação dos poderes invisíveis, das oligarquias e da representação dos interesses. Diante disso, faz-se necessário compreender a democracia como prática, de modo a expandir os seus espaços de influência e integrar-lhe uma nova dimensão deliberativa, ampliando os espaços públicos e incluindo no processo de tomada de decisão política os indivíduos e os corpos sociais por ela afetados, de maneira que possam participar, de maneira permanente, do debate público que lhe deve anteceder e acompanhar.

Dessa maneira, o presente artigo tem por objetivo geral identificar as históricas insuficiências do sistema representativo da democracia moderna e apresentar a deliberação como instrumento indispensável à mitigação do déficit democrático observado na contemporaneidade, haja vista ser capaz de colmatar lacunas do modelo tradicional e de criar contínuas oportunidades de participação dos indivíduos na formação da vontade geral.

Os objetivos específicos são divididos em quatro tópicos. O primeiro demonstrará a origem da democracia moderna, com destaque para as dificuldades de sua expansão na complexa sociedade contemporânea. No segundo tópico, será exposta a expansão do poder democrático e a persistente influência dos poderes oligárquicos e invisíveis. Em seguida, serão apresentadas algumas falhas do sistema representativo e identificada a criação de filtros à vontade popular. E, por fim, se investigará como a democracia deliberativa pode contribuir para a redução do déficit democrático inerente às limitações da dimensão representativa da democracia moderna.

$\mathrm{Na}$ metodologia, utilizou-se o método indutivo, acionando-se, ao longo da pesquisa, as técnicas do referente, das categorias, dos conceitos operacionais, do fichamento e da pesquisa bibliográfica (PASOLD, 2015). 


\section{O SURGIMENTO DA DEMOCRACIA MODERNA E AS DIFICULDADES DE EXPANSÃO DO SISTEMA REPRESENTATIVO NA SOCIEDADE CONTEMPORÂNEA}

O modelo de democracia que se denomina moderno é fruto de um desenho e articulação político-institucional que se desenvolve e se instala progressivamente a partir do século XIX, sendo defendida por Bobbio como um prolongamento natural, histórico e mesmo jurídico do liberalismo político (BOBBIO, 2018). Nesse contexto, antes de se analisar propriamente as características da democracia moderna, necessário compreender tal movimento histórico-político.

Embora possua diversas fórmulas e matizes, pode-se entender o liberalismo político como uma teoria e prática política secularizada de limitação do poder soberano surgida no século XVII, sobretudo a partir das duas Revoluções Inglesas, cujas bases filosóficas estão assentadas na doutrina dos direitos naturais, determinando uma concepção de Estado limitado em seus poderes (Estado de direito) e em suas funções (Estado mínimo), de modo que, a partir de mecanismos destinados a conter o exercício arbitrário do poder público, interfira o mínimo possível na esfera de ação dos indivíduos, demandando a igualdade perante a lei e a igualdade nos direitos (BOBBIO, 2017).

Dessa maneira, surge na história, primeiramente, o Estado liberal, consubstanciando uma organização político-jurídica instituidora da limitação da autoridade soberana e da divisão do poder estatal em esferas de competência que se limitam entre si, tendo surgido como reação aos abusos perpetrados pelo Antigo Regime e seu modelo de Estado absoluto (MERQUIOR, 2014). Trata-se de uma concepção de poder político fundamentado na neutralidade ideológica, na liberdade religiosa, nos direitos fundamentais, nas liberdades públicas e individuais (de opinião, imprensa, reunião e associação) e no governo representativo. $\mathrm{O}$ controle dos atos estatais pelos cidadãos é um apanágio do Estado liberal, visando impedir o abuso de poder pela autoridade.

Segundo Bobbio, por um processo de desenvolvimento interno e de alargamento do próprio Estado liberal, emergiu o Estado democrático, com a progressiva expansão dos direitos políticos e a ampliação do sufrágio, como uma consequência natural da concessão dos direitos de liberdade, afinal "a única garantia de respeito aos direitos de liberdade está no direito de controlar o poder ao qual compete esta garantia". O jurista italiano justifica essa 
necessária relação de dependência pela circunstância de que, historicamente, "quando [tais Estados] caem, caem juntos". Com isso, sustenta que o liberalismo é necessário para o desenvolvimento da democracia, na medida em que os direitos de liberdade são imprescindíveis para se exercer de maneira livre e real o poder democrático, e a democracia é necessária à proteção do liberalismo, na medida em que só os incentivos do poder democrático, isto é, a maior participação possível dos cidadãos na formação das decisões coletivas e no controle dos poder, podem garantir a permanência das liberdades fundamentais (BOBBIO, 2018, p. 38-39 e 51).

Merquior ensina que, com a ampliação dos efeitos provocados pela Revolução Francesa, o liberalismo passou a submeter-se às consequências da democracia, consolidando, definitivamente, as suas conquistas, principalmente com a contínua ampliação do sufrágio ocorrida a partir da década de 1870 (MERQUIOR, 2014). Nesse novo Estado democrático, constitucionaliza-se a oposição e consolida-se a investidura popular dos governantes, submetida, periodicamente, à verificação pelo povo, segundos os procedimentos estabelecidos (BOBBIO, 2004). É por tais razões que se convencionou denominar a democracia moderna de democracia liberal.

A democracia moderna ou liberal distingue-se da democracia herdada dos antigos não em relação à titularidade do poder político, pertencente ao povo, mas à maneira de se exercê-lo. Enquanto a democracia dos antigos é direta, participando os próprios cidadãos do processo de tomada de decisão coletiva, a democracia dos modernos, fruto do elo com o liberalismo, é representativa, de maneira que a decisão política é tomada, não pelos cidadãos, mas por seus representantes eleitos, sob o fundamento de ser o único modelo adequado à vastidão territorial dos grandes Estados (BOBBIO, 2017).

Também segundo Bobbio, o modelo de democracia moderna consentâneo com o Estado liberal seria o formal ou jurídico-institucional, caracterizado como fórmula política e sufrágio universal, de modo que importa apenas seu aspecto procedimental, isto é, a observância das regras necessárias para que o poder político seja efetiva e adequadamente distribuído entre a maior parte dos cidadãos possíveis, com a concorrência da livre manifestação da vontade mais ampla possível dos indivíduos para a formação da decisão coletiva, e não a ética ou substancial, que traria consigo um ideal igualitário, pressupondo a reforma da propriedade (BOBBIO, 2017). 
A democracia moderna, oriunda dessa articulação entre Estado liberal e democrático, parte do ponto de vista do indivíduo e, com isso, de uma concepção individualista e não orgânica de sociedade, cuja premissa filosófica nasce com a própria modernidade, dando primordial importância à autonomia do sujeito individualmente considerado. Pressupõe, então, a união dos indivíduos livres de uma determinada sociedade para a formação da decisão coletiva (BOBBIO, 2017), constituindo-se de "uma massa de iguais na qual o indivíduo tende a se isolar para resolver seus assuntos privados" (BERCOVICI, 2020, p. 186187).

Resta saber, no entanto, se tal pressuposto de uma democracia ideal revelou-se verdadeiro no decurso do tempo.

A esse respeito, Bobbio sustenta que a democracia moderna imaginara um Estado "sem corpos intermediários", de maneira que, entre os indivíduos e seus representantes, não existiriam sociedades particulares, importando apenas a participação do cidadão na formação das decisões coletivas, pois constituíam o centro de poder. Contudo, segundo anota, aconteceu exatamente o oposto, pois cada vez menos os indivíduos e mais os grupos, organizações, associações, partidos e sindicatos, tornaram-se protagonistas da sociedade política. Assim, na realidade, não existe "o povo como unidade ideal", mas "dividido de fato em grupos contrapostos e concorrentes", os quais passaram a titularizar a autonomia outrora conferida, ainda que idealmente, aos indivíduos (BOBBIO, 2018, p. 41-43).

Além desses grupos sociais, não se pode descuidar que o poder econômico, sobretudo em virtude do processo de aprofundamento da globalização da economia financeira, tem exercido, de maneira progressiva e expansiva, uma decisiva influência na condução dos assuntos públicos, inclusive de maneira oculta e fora das regras e controles democráticos, provocando, como anota Castells, a ruptura do vínculo subjetivo entre o que os cidadãos desejam e as ações realizadas pela classe política (CASTELLS, 2018). Tem-se, nesse cenário, portanto, e diferentemente do que pressupunha a doutrina democrática tradicional, uma sociedade poliárquica ou policêntrica, com a distribuição de vários centros de poder, reduzindo-se cada vez mais a autonomia dos indivíduos (BOBBIO, 2018).

Dessa maneira, limitar a democracia moderna ao seu sistema representativo, restrito à sua forma política, procedimentos e eleições periódicas, contribui para a manutenção desse estado de coisas que confere aos indivíduos uma participação meramente episódica e restrita à escolha dos seus representantes, mas não da efetiva tomada das decisões coletivas. Significa 
anuir com a substituição da influência da cidadania na formação da vontade geral pelos diversos centros de poder dessa sociedade pluralista, muitos dos quais ocultos, perpetuando as históricas dificuldades que se impõem à constituição de um real governo popular.

Não se ignora os avanços proporcionados pelo sufrágio universal, mas a democracia deve expandir o seu campo de realização, principalmente quando se considera que, a despeito desse avanço, o seu modelo liberal criou ao longo do tempo verdadeiros filtros da vontade popular que, sob o pretexto de reduzirem os riscos que adviriam do exercício de um poder popular irrestrito, qualificam-se como autênticos mecanismos antidemocráticos, demandando o reconhecimento e correção dessas deficiências, consoante abaixo será exposto.

\section{A EXPANSÃo dO PODER DEMOCRÁTICO E A PERSISTENTE INFLUÊNCIA DOS PODERES OLIGÁRQUICOS E INVISÍVEIS}

Dentre os fundamentos utilizados para a adoção do modelo representativo da democracia moderna, destaca-se o de que seria a única forma possível de se praticar o governo popular em Estados de grande vastidão territorial como são os Estados modernos. Todavia, resta saber até que ponto tal questão foi, também, influenciada pelos poderes oligárquicos que se recusavam submeter-se ao governo democrático, de maneira que o poder político permanecesse, efetivamente, sendo exercido por alguns poucos indivíduos, em virtude do receio, nem sempre racional e confessadamente justificado, de se deixar as questões do Estado inteiramente nas mãos dos cidadãos. Algumas circunstâncias, sobretudo históricas, podem corroborar tal modo de pensar.

Por decorrência da desconfiança do liberalismo em relação à forma de governo popular, o sufrágio permaneceu restrito em grande parte do século XIX (BOBBIO, 2017). Bercovici sustenta que, nesse século, a grande questão político-constitucional foi, de fato, o sufrágio universal, cujo alcance ocorreu de maneira não linear, entre emancipação e desemancipação. Inclusive, divergindo de Bobbio e com fundamento nos escritos de Losurdo, entende que o sufrágio universal foi alcançado em momentos históricos hostis à tradição liberal, como a radicalização jacobina da Revolução Francesa, a partir de 1792, a Revolução de fevereiro de 1848 e a Revolução Russa de 1917. Com base nisso, o referido autor conclui que "não procede a afirmação de Norberto Bobbio de que houve um desenvolvimento espontâneo do liberalismo em relação à democracia” (BERCOVICI, 2020, p. 186-187). 
O Estado liberal, em seu nascimento, manteve o poder político distanciado do poder democrático, de maneira que o governo - entendido como o aparato pelo qual o poder soberano é exercido, cujas formas diferenciam-se em virtude da diversidade das pessoas dele encarregadas (ABBAGNANO, 2012) -, permanecia nas mãos de poucos indivíduos (BOBBIO, 2017), em regra da classe possuidora, de maneira que o sufrágio estava diretamente interligado ao patrimônio (voto censitário). Nesse sentido, Bercovici anota que o sufrágio universal foi alcançado "entre discriminação censitária (e o consequente preconceito contra o trabalho assalariado) e radicalização dos excluídos" (BERCOVICI, 2020, p. 187). Ferrajoli também anota que "até mesmo o pensamento liberal mais iluminado" possuía repulsa pela igualdade, pois restringia o sufrágio apenas aos cidadãos instruídos ou proprietários, pois supostamente os únicos capazes de se autodeterminarem e, com isso, possuírem autonomia política (FERRAJOLI, 2015, p. 44).

Isso decorria de uma desconfiança do liberalismo em relação ao governo popular, haja vista alguns perigos que lhe seriam inerentes, como a tendência, segundo já anotava Heródoto, de se degenerar politicamente em direção à demagogia ou, segundo Platão, à tirania (ABBAGNANO, 2012). Trata-se do antigo risco da onipotência ou tirania da maioria, cuja ameaça foi percebida de Cícero ${ }^{1{ }^{1}}$ aos autores liberais dos séculos XVIII e XIX, como Madison (ZAKARIA, 2004), Tocqueville (TOCQUEVILLE, 2019) e Mill (BOBBIO, 2017), derivada da sempre presente tensão entre a limitação do poder e respeito às liberdades fundamentais e a amplitude do exercício do poder político legitimado pela soberania popular. Tal onipotência diz respeito a um suposto poder irresistível que interferiria "em todos os detalhes da vida social dos cidadãos, mas que se caracteriza por ser tutelar, não tirânico" (BERCOVICI, 2020, p. 190), na medida em que não envolveria uma violência material e o próprio povo escolheria os seus tutores.

Tal circunstância, relacionada às resistências do poder oligárquico, certamente consubstancia uma das razões pelas quais o sufrágio permaneceu restrito durante tanto tempo, enfrentando fortes resistências em cada etapa histórica da sua extensão até alcançar o ideal limite do sufrágio universal masculino e feminino. Bercovici registra que "os defensores do

\footnotetext{
1 “A nenhum Estado negarei tanto esse nome [República] como àquele em que tudo está sob o poder da multidão. [...] não creio que corresponda mais o nome de República ao despotismo da multidão, porque o povo não está para mim, como tu ontem. Cipião, disseste muito bem, se não existe o consentimento pleno de direito, sendo esse conjunto de homens tão tirano como se fosse um só e tanto mais digno de ódio quanto nada há de mais feroz do que essa terrível fera que toma o nome e imita a forma do povo”. (CÍCERO, 2011, p. 90)
} 
voto censitário sempre viram a extensão do sufrágio como uma violação das regras do jogo, pois atingiria o próprio direito de propriedade e sua proteção constitucional” (BERCOVICI, 2020, p. 187). Tal restrição, sob o argumento de que a expansão do direito ao voto ameaçava à liberdade, repousa em forte desprezo à influência das massas políticas.

Trilhando semelhante caminho, a democracia representativa parte da premissa de que "os representantes eleitos pelos cidadãos estariam em melhores condições de avaliar quais seriam os interesses gerais do que os próprios cidadãos, fechados demais na contemplação de seus próprios interesses particulares" (BOBBIO, 2017, p. 58-59). Há, portanto, uma forte herança histórica e paternalista de afastamento dos indivíduos do processo de tomada de decisões que não pode ser ignorada. Vejam-se outros elementos históricos que corroboram essa assertiva.

Com uma motivação similar ao argumento acima, mas defendendo o voto censitário, Constant, de acordo com Bercovici, entendia que "a exclusão dos não-proprietários se justificaria pela sua falta de independência para decidir sobre os seus interesses", de maneira que, "acaso pudessem votar, como são a maioria, utilizariam o seu poder para violar a propriedade e destruiriam a sociedade liberal" . Com o mesmo receio, mas sem a defesa do voto censitário, Tocqueville, também de acordo com Bercovici, e tomando por base o modelo norte-americano, defendia "um sistema eleitoral de vários graus, para proteger a representação da influência das massas", de maneira que, mediante a "depuração social dos órgãos representativos", evitava-se os riscos de uma "instabilidade do sufrágio universal pleno"(BERCOVICI, 2020, p. 188). Embora defendesse um sufrágio mais ampliado, Mill restringia-o apenas a quem pagasse impostos, excluindo os falidos, devedores fraudulentos, analfabetos e os que vivem de esmolas, além de conferir aos mais instruídos e intelectualmente capazes o voto plural, mitigando os efeitos políticos da extensão do sufrágio e, por conseguinte, filtrando a vontade popular (BOBBIO, 2017).

Tais circunstâncias contribuíram para a manutenção da influência dos grupos oligárquicos no Estado democrático moderno, mantendo uma consciência de que os cidadãos seriam incapazes de tomar decisões racionais, necessitando de corpos intermediários e de um sistema de representação cujos atores são oriundos, via de regra, das elites da sociedade, supostamente mais capazes para a tomada de decisão. Não à toa, Bobbio insere a permanência das oligarquias como uma das promessas não cumpridas da democracia, não tendo se revelado capaz de derrotar a participação e influência dominante de tal poder na formação das 
vontades gerais, muito embora tenha por mérito possibilitado a surgimento da concorrência entre as mais diversas elites, mediante eleições livres (BOBBIO, 2018). Todavia, a despeito desse avanço, não há dúvida de que "as oligarquias têm a capacidade de minar o aperfeiçoamento democrático, reforçando os piores ranços da política” (SCHWARCZ, 2019, p. 61-62), na medida em que são concedidas vantagens políticas que garantem a manutenção desse poder herdado ou construído ao longo do tempo.

No Brasil, a permanência do poder oligárquico é retratado por Schwarcz, ao narrar a histórica influência e o consequente acúmulo de poder das elites locais no cenário políticoeleitoral do país, sobretudo por intermédio de integrantes do mesmo núcleo familiar ou de famílias distintas que se revezam no poder, os quais são responsáveis por praticar "mandonismo político, cultural e social há longa data em suas regiões de origem" (SCHWARCZ, 2019, p. 57-63). A esse respeito, traz à tona os casos dos Estados de Maranhão (família Sarney), Ceará (família Ferreira Gomes), Rio Grande do Norte (família Alves), Goiás (famílias Caiado e Bulhões), Acre (família Viana) e Alagoas (família Calheiros), cujos políticos tradicionais se perpetuaram ou perpetuam no poder por décadas ou, no caso de Goiás, por mais de século (desde o século XIX).

De certo modo relacionado à resistência dos poderes oligárquicos e conquanto torne aparente o exercício do que, historicamente, permanecia oculto, o sistema representativo não conseguiu livrar-se da influência dos poderes invisíveis que, por definição, e remontando ao Estado absoluto, são antidemocráticos, na medida em que recusam submeter-se ao princípios da visibilidade e da transparência do poder. Nesse contexto, Bobbio sustenta que "o princípio da visibilidade do poder é inatural", sendo, por isso, "o mais difícil de ser respeitado", motivo pelo qual o poder sempre encontrará pretextos e argumentos para não ser transparente (BOBBIO, 2018, p. 51 e 298).

Essa necessária publicidade inerente ao governo democrático está ligada não somente aos atos propriamente ditos, mas também às suas intenções e motivações, afinal "o poder autocrático não apenas se esconde para que não se saiba quem é ele e onde está, mas tende também a esconder suas reais intenções no momento em que suas decisões devem tornar-se públicas". E, segundo Bobbio, muito embora a democracia tenha nascido "com a perspectiva de eliminar para sempre das sociedades humanas o poder invisível e de dar vida a um governo cujas ações deveriam ser desenvolvidas publicamente" - tanto por possibilitar o exercício de controle dos atos de governo pelos cidadãos, como também "porque a 
publicidade é por si mesma uma forma de controle" -, o fato é que tal promessa não foi cumprida pelo modelo de democracia que se impôs à realidade, principalmente em relação ao governo da economia, pois não se submete, ao menos substancialmente, ao controle democrático e mesmo jurisdicional (BOBBIO, 2018, p. 52-54, 139-140, 152-153 e 163-164).

Por fim, reunindo a desconfiança do liberalismo em relação ao avanço do poder democrático e a permanência dos poderes invisíveis, vale o registro do que se tem denominado de sobrecarga de demandas. Trata-se de uma suposta ingovernabilidade da democracia identificada pelos economistas, os quais alegam que o Estado, por influência do sufrágio universal, teria aumentando o seu aparato burocrático, deixado de ser mínimo e, com isso, posto o capitalismo e a própria concepção Estado liberal em risco. Isso porque, à medida em que a democracia se desenvolveu, o Estado teve que fazer frente às novas demandas sociais vindas de baixo, das classes que progressivamente conquistaram o direito ao voto, sobretudo dos não proprietários. Assim, como reflexo da expansão da titularidade dos direitos políticos, emergiu o Estado social. Como solução a essa expansão do processo de burocratização, tem-se defendido a redução do poder político do Estado e ampliação do poder do mercado econômico, ainda que à custa das demandas democráticas, reduzindo tal poder "a limites bem circunscritos" (BOBBIO, 2018, p. 61-62 e 192-199).

Diante desse quadro de promessas não cumpridas, até que ponto a redução da democracia à garantia da fórmula política e das regras do jogo democrático do sistema representativo não tem, em verdade, contribuído para a manutenção do déficit democrático que remonta ao século XIX e aos vetustos receios em relação ao avanço do poder democrático e, além disso, para o próprio enfraquecimento do governo popular.

\section{ALgUMAS FALHAS DO SISTEMA REPRESENTATIVO E A CRIAÇÃO DE FILTROS À VONTADE POPULAR: A FICÇÃO DA SOBERANIA POPULAR, A FALÁCIA DO AUTOGOVERNO E O FRACASSO DA PROIBIÇÃO DE MANDATO IMPERATIVO}

Antes de demonstrar o papel que a deliberação pública pode desempenhar na redução do déficit democrático do sistema representativo, impende enfrentar, ainda que brevemente, algumas questões alusivas à soberania popular e ao autogoverno, sobretudo porque 
comumente utilizadas como argumento defensivo da suficiência do atual modelo de democracia moderna.

A primeira diz respeito à soberania popular subjacente ao poder democrático. É importante considerá-la como uma mera ficção e não como uma evidência a legitimar toda e qualquer decisão tomada pelos representantes políticos, sobretudo se considerada a complexidade, pluralidade e heterogeneidade da sociedade moderna. A propósito, convém registrar que a concepção rousseauniana de vontade geral e de soberania popular foi desvirtuada pelos revolucionários franceses, cujo resultado foi legado à democracia moderna. Enquanto Rousseau defendia que a vontade geral deveria ser manifestada nas assembleias periódicas, distanciadas do Poder e com a participação direta do povo - atribuindo-se-lhes um papel negativo, semelhantemente ao referendo -, e não por intermédio de representantes, os atores da Revolução Francesa defendiam que a vontade geral somente poderia ser representada pelo Parlamento, "que se tomou imediatamente habilitado não apenas a manifestar, mas a formar essa vontade", afastando-se os indivíduos, agora meramente representados, desse processo. Assim, em verdade, as decisões políticas não representam, a rigor, a vontade geral - certamente inalcançável -, mas a vontade legislativa parlamentar ou mesmo de sua fração dominante (JOUVENEL, 1998, p. 308-314 e 363-364).

Aliás, porque tal ficção pode encobrir situações muito díspares e pode servir de fundamento para a adoção de medidas autoritárias e violadoras de direitos fundamentais por políticos que se atribuam a qualidade de representantes dessa vontade geral, Bobbio entende mais adequado tratar de uma soberania dos cidadãos, até mesmo em razão da ambiguidade e abstração que integram o conceito de "povo" e porque "a sociedade democrática não é um corpo orgânico, mas uma soma de indivíduos", com suas diferenças e diversidades. Mais do que o poder do povo, a democracia moderna deve ser definida como "o poder dos indivíduos tomados um a um" (BOBBIO, 2004, p. 95 e 109), com suas peculiaridades e divergências.

Outra importante questão, relacionada diretamente com o que se disse acima, diz respeito à ideia falaciosa ${ }^{2}$ do autogoverno, segundo a qual, na democracia, os indivíduos submetem-se às leis e atos produzidos por si mesmos. Ferrajoli alerta que "na democracia representativa o voto popular contribui apenas para a eleição de quem é chamado a decidir,

\footnotetext{
2 "Falácias são erros lógicos, conscientes ou inconscientes, enganadores e/ou autoenganadores, que servem para ludibriar e formar pré-compreensões equivocadas, conducentes a preconceitos ilegítimos, estereótipos e más decisões". (FREITAS, 2016, p. 143)
} 
mas não tem nada a ver com as decisões dos eleitos", inclusive nem mesmo na eleição é possível prever o mérito do que será deliberado no futuro pela classe política dos representantes. Os indivíduos não participam, assim, da formação das decisões políticas, mas se limitam à escolha dos governantes, isto é, daqueles a quem incumbirá tal tarefa, e, inclusive, sofrem os efeitos de decisões que procuram alijá-los desse processo. Por tal razão, as normas permanecem como medidas heterônomas, pois não são produzidas pelos próprios cidadãos por ela afetados, o que leva à rejeição do impróprio excesso de legitimação conferido ao poder político pelo argumento de que a democracia representativa retrataria um autêntico autogoverno popular (FERRAJOLI, 2015, p. 42-45).

Dessa maneira, permitir que a democracia moderna limite-se à sua fração representativa apenas contribuirá para o aprofundamento da crise de representatividade política vivenciada pelas instituições eletivas e da apatia política observada nas democracias contemporâneas. Primeiro, porque tal sistema não garante, como se viu, que a vontade política encontre ressonância na conjuntura social, mas apenas que corresponda aos desejos de autoconservação da classe política dominante (BOBBIO, 2004), e, não menos relevante, porque não enfrenta as causas daquela crise, consistentes no "desaparecimento do embasamento social dos partidos" e consequente descrédito popular, na "crescente personalização e verticalização dos sistemas políticos", na "tendência destes a se sujeitarem aos poderes econômicos e financeiros" e no desenvolvimento de movimentos populistas (FERRAJOLI, 2015, p. 45).

Por fim, o último filtro da vontade popular legado pelos movimentos liberais do século XVIII à democracia moderna que vale mencionar neste artigo, dada a limitação da sua problematização, diz respeito à proibição de mandato imperativo, defendida por Sieyès já na sessão constituinte de 07/07/1789 (JOUVENEL, 1998) e adotada pela primeira vez na Constituição francesa de 03/09/1791 (FERRAJOLI, 2015). Tal instituto foi concebido para se extinguir, como ocorria no Estado de estamentos, a vinculação entre o eleitor e o representante eleito, pela qual "os estamentos, as corporações e os corpos coletivos transmitiam ao soberano, por meio de seus delegados, suas reivindicações particulares" e que, acaso não fossem defendidas nos limites do mandato conferido, acarretava a perda do direito de representação. Assim, o mandato livre libertaria "o indivíduo em sua singularidade", cabendo a ele, e não mais ao membro de corporação, "o direito de eleger os representantes da 
nação", cujo interesse buscado, portanto, passaria a ser de todo o seu conjunto (bobbio, 2017, p. 58-60).

No entanto, como ressalta Bobbio, "jamais uma norma constitucional foi mais violada que a da proibição de mandato imperativo". É que, em realidade, os representantes substituíram o que deveria ser a busca pelos interesses gerais e coletivos da nação (representação política) para tutelar interesses particulares de grupos de pressão (interesses econômicos, p. ex.), dos seus partidos ou mesmo passaram a identificar o interesse nacional como o do próprio grupo (representação dos interesses). Então, tal medida contribuiu não somente para a permanência da defesa de interesses particulares, embora de maneira não transparente, como, por se tratar de regra sem sanção, tornou os representantes irresponsáveis perante os seus eleitores, aprofundando a crise representativa observada na contemporaneidade. À vista disso, embora desvirtuada em sua finalidade - representação dos interesses gerais da sociedade -, o mandato permaneceu irrevogável, resultando em um cenário pior do que o figurado no Estado de estamentos, afinal, lá o delegado atuava de maneira explícita nos limites da representação e era passível de destituição (BOBBIO, 2018, p. 45-46, 78-79 e 215-216).

A esse respeito, por fim, não se pode descuidar da dificuldade prática para se alcançar o desiderato idealizado de se identificar o interesse geral, sobretudo em sociedades plurais, complexas e parciais como a contemporânea, tornando inviável a pretendida representação da universalidade, o que impõe sejam repensados os tradicionais mecanismos democráticos modernos.

\section{A TRANSFORMAÇÃO DA DEMOCRACIA MODERNA E A REDUÇÃO DO SEU DÉFICIT DE REPRESENTATIVIDADE PELA INTEGRAÇÃO DA DELIBERAÇÃO PÚBLICA}

É no contexto exposto acima que devem ser instituídos mecanismos de participação popular incumbidos de impedir que os membros da sociedade sejam "cidadãos somente um dia e súditos por quatro anos" e, com isso, evitar que o exercício da soberania popular permaneça ligada ao povo apenas pelo "cordão umbilical muito frouxo das eleições gerais" (JOUVENEL, 1998, p. 328-329). 
Emerge, portanto, a importância do papel desempenhado pela deliberação pública nas democracias modernas, partindo-se da premissa de que "a democracia já não se limita ao momento do voto periódico, mas é feita de um debate público contínuo que deve acompanhar as decisões políticas", tendo a sociedade civil por protagonista, mediante a "troca de argumentos, o oferecimento de razões e a justificação das decisões que afetem a coletividade" (VIEIRA, 2017, p. 569). Como anota Souza Neto, a democracia deliberativa surge, no final do século XX, como alternativa às teorias liberais que reduzem a democracia à "escolha de elites governantes" ou a um restrito processo que envolva apenas a "prerrogativa popular de eleger representantes", de maneira, então, que também passe a integrar "a possibilidade efetiva de se deliberar publicamente sobre as questões a serem decididas", com a apresentação de argumentos e contra-argumentos que possam racionalizar e legitimar as decisões públicas, evitando-se a histórica manipulação do sistema representativo (SOUZA NETO, 2009, p. 79).

Held define a democracia deliberativa como a teoria que aloca o núcleo do legítimo processo de tomada de decisão e do autogoverno na deliberação pública entre cidadãos livres e iguais e não apenas no resultado das urnas ou nas regras da maioria. Nesse contexto, a legitimidade política está relacionada à prestação de contas e à apresentação de razões e explicações acerca das decisões públicas, transformando, pelo processo de deliberação, preferências privadas em posições que possam resistir ao escrutínio público. A sua prática, portanto, é capaz de corrigir ou mitigar algumas das falhas e filtros de vontade popular do sistema representativo, como as vistas acima, aumento a qualidade do processo democrático de tomada de decisão (HELD, 2006).

De acordo com Souza Neto, para que a deliberação possa ser realizada de maneira justa e efetiva, deve permitir que todos possam dela participar, em igualdade de possibilidades e capacidades de influir e persuadir, em um contexto livre e aberto e sem qualquer modalidade de coerção. Além disso, exige-se "que a democracia abarque, em regra, um momento deliberativo pré-decisório" (SOUZA NETO, 2009, p. 79-80), a fim de que a decisão seja construída de maneira plural, racional e legítima, com a explicitação das razões que lhe justificam e motivam, evitando-se a tradicional influência dos poderes ocultos.

A institucionalização da deliberação pública tem o condão de reduzir o déficit da representatividade política e atribuir maior legitimidade às instituições, proporcionando uma atuação mais participativa da cidadania e dos corpos sociais organizados na formação das decisões públicas, integrando-a, permanentemente, aos processos de tomada de decisão, 
modificando, pelo compartilhamento de informações e conhecimento, perspectivas individuais de problemas complexos (HELD, 2006). Segundo Brandão, com a adoção de mecanismos deliberativos, busca-se que "os participantes considerem seriamente a perspectiva do outro, reconhecendo os seus eventuais méritos e desconsiderando desacordos sobre aspectos não essenciais à resolução de questão controvertida", transformando "as preferências cruas de maiorias ocasionais no julgamento refletido da comunidade" (BRANDÃO, 2017, p. 263-267), em benefício de muitos.

Tal dimensão da democracia contemporânea pode funcionar como importante mecanismo para equilibrar os poderes exercidos na democracia representativa, na medida em que incentiva a ampliação dos espaços públicos e, com isso, o revigoramento da coesão social, mitigando a influência dos poderes oligárquicos. Além disso, pela abertura e amplitude do debate público para a formação das decisões nas esferas políticas e, inclusive, jurisdicionais, proporciona que os diversos centros de poder da sociedade pluralista não somente sejam limitados entre si, mas também passem a submeter-se aos influxos do poder democrático.

A deliberação pública impõe a inclusão no processo democrático dos indivíduos afetados, em um momento pré-decisório. Tão importante quanto rechaçar as atitudes políticas que violem direitos está impedir que se "exclua o elemento democrático e participativo dos cidadãos", na medida que as duas situações qualificam formas autoritárias de governo (GODOY, 2012, p. 71). A propósito, Souza Neto e Sarmento defendem que "não há como efetivar uma Constituição sem a mobilização ativa da cidadania" (SOUZA NETO; SARMENTO, 2013, p. 444), necessitando-se, por isso, de um ambiente cada vez mais fértil ao debate público e adequado à deliberação democrática, de modo a engajar toda a sociedade no seu aprimoramento e na sua efetividade.

A deliberação pública auxilia na mitigação dos efeitos dos filtros à vontade popular que se instauraram ao longo da consolidação da democracia liberal, permitindo que surjam novos processos de associação e outras formas de participação democrática para além dos partidos políticos e do exercício do voto, de que são exemplos "as consultas populares, as assembleias de políticas públicas, as conferências de consenso, as mesas de diálogo e controvérsia, a gestão municipal participativa” (CRUZ, 2014, p. 146), além das já consagradas audiências públicas. 
Quando não há previsão de procedimentos formais de participação contínua dos indivíduos na formação das decisões políticas, mas apenas eleições periódicas de quem verdadeiramente decidirá, livremente, no que se consubstancia a vontade geral, tem-se observado que, quando a insatisfação alcança níveis incontroláveis, resta aos cidadãos forçar a sua participação, de maneira informal, por intermédio das grandes manifestações populares que, sem espaço nos procedimentos pré-decisórios, encontram na ocupação das ruas e demais espaços públicos o local para fazer ouvir a sua vontade reprimida. Trata-se de um sintoma da ausência de espaços aos indivíduos nas deliberações que devem acompanhar as decisões coletivas e uma notória prova da necessidade de desenvolvimento da democracia deliberativa.

A dimensão deliberativa, com o permanente debate público que deve preceder a tomada de decisões políticas e a integração da participação da sociedade nos momentos prédecisórios, impede seja reconhecida "a assembleia como um simples meio de obter o Poder e o povo como um simples meio de preencher a assembleia" (JOUVENEL, 1998, p. 339). Com base nos escritos de Habermas, Cavedon e Vieira ensinam que "a legitimidade de decisões depende dos processos de formação da opinião e vontade na periferia, pois o centro do sistema, representado pelas instituições público-políticas, controla só parte deste processo e precisa se retroalimentar na periferia" (CAVEDON; VIEIRA, 2011, p. 64). E, a esse respeito, não há dúvida de que os mecanismos de deliberação público podem desempenhar tal papel, devendo o Estado garantir não apenas as liberdades negativas, mas também as liberdades comunicativas, incentivando e ampliando a participação dos cidadãos no debate público e a sua integração ao processo de deliberação e formação das decisões públicas (HABERMAS; RATZINGER, 2007).

Abbagnano anota que a história moderna e contemporânea tem demonstrado que a liberdade e o bem-estar dos cidadãos dependem mais da sua participação na formação da vontade geral que a forma de governo propriamente dita (ABBAGNANO, 2012). Na mesma toada, tratando da importância das liberdades substantivas para o desenvolvimento, Sen destaca os incentivos políticos que apenas o sistema democrático pode proporcionar para o atendimento das necessidades gerais, sublinhando a importância da capacidade dos indivíduos exercida não somente pelo voto, mas também ao expressar e defender as suas reivindicações que exijam atenção política, o que é sobremaneira intensificado pela abertura do processo de formação das políticas governamentais à deliberação dos indivíduos afetados, sobretudo se se considerar que a representação política, como se viu, é livre, não garantindo, por si só, o 
atendimento da vontade geral. O mesmo autor destaca, ainda, que as instituições democráticas não podem ser vistas como dispositivos mecânicos, demandando oportunidades de articulação e participação, cujo cultivo às discussões e debates públicos podem “fazer com que a própria democracia funcione melhor" (SEN, 2010, p. 195, 197-199, 201 e 208).

\section{CONSIDERAÇÕES FINAIS}

Apesar dos inegáveis avanços que a democracia representativa trouxe às liberdades substantivas e políticas, o seu aperfeiçoamento passa pelo reconhecimento da sua insuficiência à sociedade contemporânea e, por conseguinte, pela análise e superação de suas deficiências encontradas na prática e que, em grande parte, são fruto de resistências impostas pelos poderes oligárquicos.

A adoção de uma prática mais integral da democracia, conforme exposto neste ensaio, com a adoção de mecanismos deliberativos, tem o condão de ampliar os espaços públicos e incluir no processo de tomada de decisão política os indivíduos e os corpos sociais por ela afetados, mitigando-se a influência dos poderes ocultos e atribuindo-se maior responsabilidade aos representantes políticos.

Portanto, devem ser garantidos e fortalecidos os instrumentos políticos e jurídicos de controle das instituições democráticas que, sobretudo, contribuam e garantam para uma maior participação e articulação dos cidadãos na formação das decisões políticas, de maneira a permitir uma maior e constante influência popular, corrigindo as falhas e atenuando os efeitos provocados pelos filtros estabelecidos ao longo da tradição da democracia moderna e destinados a provocar uma espécie de depuração social dos órgãos representativos.

E, a esse propósito, os mecanismos de democracia deliberativa são capazes de integrar, de maneira permanente, a população ao processo de formação das leis e das políticas públicas, sobretudo aquela parcela que possui maior dificuldade de "se fazer ouvir" em democracias precipuamente formais como a do Brasil que, segundo Holanda, "foi sempre um lamentável mal-entendido" (HOLANDA, 2014, p. 191-192).

\section{REFERÊNCIAS}


ABBAGNANO, Nicola. Dicionário de filosofia. Trad. coord. Alfredo Bosi. 6. ed. São Paulo: Editora WMF Martins Fontes, 2012.

BERCOVICI, Gilberto. Soberania e Constituição: para uma crítica do constitucionalismo. 3. Ed. São Paulo: Quartier Latin, 2020.

BOBBIO, Norberto. A era dos direitos. Tradução de Carlos Nelson Coutinho. Rio de Janeiro: Elsevier, 2004.

, Norberto. Liberalismo e democracia. Tradução de Marco Aurélio Nogueira. São Paulo: Edipro, 2017.

, Norberto. O futuro da democracia: uma defesa das regras do jogo. Tradução de Marco Aurélio Nogueira. 15. Ed. São Paulo: Paz e Terra, 2018.

BRANDÃO, Rodrigo. Supremacia judicial versus diálogos constitucionais: a quem cabe a última palavra sobre o sentido da constituição?. Rio de Janeiro: Lumen Juris, 2017.

CASTELLS, Manuel. Ruptura: a crise da democracia liberal. Tradução de Joana Angélica d'Avila Melo. Rio de Janeiro: Zahar, 2018.

CAVEDON, Fernanda de Salles; VIEIRA, Ricardo Stanziola. A política jurídica e o direito socioambiental: uma contribuição para a decidibilidade dos conflitos jurídico-ambientais. Novos Estudos Jurídicos, Itajaí, v. 16, n. 1, jan./abr. 2011.

CÍCERO, Marco Túlio. Da República. Tradução de Amador Cisneiros. 2. ed. São Paulo: Edipro, 2011, p. 90

CRUZ, Paulo Márcio. Da soberania à transnacionalidade: democracia, direito e Estado no século XXI. Itajaí: Univali, 2014.

FERRAJOLI, Luigi. A democracia através dos direitos: o constitucionalismo garantista como modelo teórico e como projeto político. Tradução de Alexander Araújo de Souza et al. São Paulo: Revista dos Tribunais, 2015.

FREITAS, Juarez. Sustentabilidade: direito ao futuro. 3. ed. Belo Horizonte: Fórum, 2016.

GODOY, Miguel Gualano de. Constitucionalismo e democracia: uma leitura a partir de Carlos Santiago Nino e Roberto Gargarella. São Paulo: Saraiva, 2012.

HABERMAS, Jürgen; RATZINGER, Joseph. Dialética da secularização: sobre razão e religião. Tradução Alfred J. Keller. Aparecida: Ideias \& Letras, 2007. 
HELD, David. Models of Democracy. 3. ed. California: Stanford University Press, 2006.

HOLANDA, Sérgio Buarque de. Raízes do Brasil. 27. ed. São Paulo: Companhia das Letras, 2014.

JOUVENEL, Bertrand de. O Poder: história natural de seu crescimento. Tradução de Paulo Neves. São Paulo: Peixoto Neto, 1998

MERQUIOR, José Guilherme. O liberalismo: antigo e moderno. Tradução de Henrique de Araújo Mesquita. 3. Ed. São Paulo: É Realizações, 2014.

PASOLD, Cesar Luiz. Metodologia da pesquisa jurídica. 13. Ed. Florianópolis: Conceito Editorial, 2015.

SCHWARCZ, Lilia Moritz. Sobre o autoritarismo brasileiro. São Paulo: Companhia das letras, 2019.

SEN, Amartya. Desenvolvimento como liberdade. Tradução Laura Teixeira Motta. São Paulo: Companhia das Letras, 2010.

SOUZA NETO, Cláudio Pereira de. Deliberação púbica, constitucionalismo e cooperação democrática. In: SARMENTO, Daniel (Coord.). Filosofia e teoria constitucional contemporânea. Rio de Janeiro: Lumen Juris, 2009.

Cláudio Pereira de; SARMENTO, Daniel. Direito constitucional: teoria, história e métodos de trabalho. Belo Horizonte: Fórum, 2013.

TOCQUEVILLE, Alexis de. A democracia na américa. Tradução de Julia da Rosa Simões. São Paulo: Edipro, 2019.

VIEIRA, Oscar Vilhena; Glezer, Rubens (Org.). A razão e o voto: diálogos constitucionais com Luís Roberto Barroso. Rio de Janeiro: FGV Editora, 2017.

ZAKARIA, Fareed. The future of freedom: Illiberal democracy at home and abroad. New York: W. W. Norton \& Company, Inc., 2004. 